\title{
Combating COVID-19: Nigerian Nurses' Perspectives and Challenges Executive Summary
}

\author{
Grace Ogiehor-Enoma ${ }^{*}{ }^{(0)}$, Dorothy C. Nwanonyiri ${ }^{2}$ (D) Emilia Iwu ${ }^{3}$, \\ Ednah N. Madu ${ }^{4}$, Assumpta Ekeh $^{5}$ ( , Ruth Ifediora ${ }^{6}$ \\ ${ }^{1}$ Hunter-Bellevue School of Nursing, Hunter College, New York, NY, USA \\ ${ }^{2}$ Felician University, Lodi, New Jersey, USA \\ ${ }^{3}$ School of Nursing, Rutgers University Newark, NJ, USA \\ ${ }^{4}$ College of Nursing and Public Health, Adelphi University, Garden City, New York, USA \\ ${ }^{5}$ College of Nursing, Seton Hall University, South Orange, NJ, USA \\ ${ }^{6}$ Parkland Health and Hospital System, Dallas, Texas, USA \\ Email: ^ogiehororhue@aol.com
}

How to cite this paper: Ogiehor-Enoma, G., Nwanonyiri, D.C., Iwu, E., Madu, E.N., Ekeh, A. and Ifediora, R. (2020) Combating COVID-19: Nigerian Nurses' Perspectives and Challenges Executive Summary. Open Journal of Nursing, 10, 1265-1274. https://doi.org/10.4236/ojn.2020.1012092

Received: October 13, 2020

Accepted: December 28, 2020

Published: December 31, 2020

Copyright $\odot 2020$ by author(s) and Scientific Research Publishing Inc. This work is licensed under the Creative Commons Attribution International License (CC BY 4.0).

http://creativecommons.org/licenses/by/4.0/

\begin{abstract}
Coronavirus disease 2019 (COVID-19) is one of the worst deadly infections that is currently causing devastating effects and damages to humanity across the world. The global pandemic which outbroke in Wuhan in China has equally affected almost every country in the world. Over the past several months of the coronavirus crisis, cities went into lockdown, countries issued stay-at-home orders, and an increasing number of people had been practicing social distancing on a societal scale that has never been witnessed. However, nurses continue to provide care, comfort, and information to patients at all levels while risking their personal safety and well-being. This executive report provides an insight in Nigerian nurses' perspectives and challenges in combating COVID-19 during the surge. Capturing nursing practice and nurses' experiences during COVID-19 surge provide real-time guidance to mitigating challenges and improving well-being of nurses.
\end{abstract}

\section{Keywords}

COVID-19 Pandemics, Nurses Experiences, Preparedness and Response, Nigerian Nurses

\section{Introduction}

In the face of a global infectious disease outbreak such as the Coronavirus 
(COVID-19) pandemic, people experience unprecedented challenges. These challenges may intensify for some individuals especially those on the frontline of care for people diagnosed with COVID-19 such as nurses. Historically, nurses consistently play vital roles in health promotion and disease prevention, as advocated by Florence Nightingale [1]. Although, nurses serve as one of the most needed professional groups during pandemics, they are equally at higher risks for emotional impact of caring for their patients which can result in work-related anxiety and other mental health issues [2] [3]. Nurses frequently demonstrate and exhibit a sense of duty and dedication to patient care but often, nurses are the least recognized during health crisis especially in low- and mid-income countries. However, the occurrence of COVID-19 pandemic during the "Year of the Nurse and Midwife" has amplified nurses' tenacity and "dedication to patients, families, and communities" [4]. It has also exposed nurses' vulnerability in the areas of occupational risks when health systems are ill-equipped to provide necessary protective equipment (PPE). In sub-Sahara Africa, these vulnerabilities are worse as nurses report lack of training for COVID-19 care in addition to other poor working conditions [5].

\section{Background and Objectives}

During the COVID-19 pandemic, nurses experienced enormous pressures as they battle with the life-threatening virus and inadequate supply of personal protective equipment (PPE) in most facilities; therefore, putting their own lives and that of their family members at risk [1]. Nurses continue to be on duty every day with great uncertainty when the rest of the world stays home. Despite all odds, nurses stay on the front-line of care, directly touching patients while others maintain physical and social distancing. As a result of strict hospital isolation protocols which limit family members' visits, the role of nurses in providing care for patients diagnosed with COVID-19 takes on a different dimension. In addition to regular nursing care, they also substitute as "patients' family members." It is also crucial to note that nurses are affected emotionally by high death rates associated with COVID-19 [6]. Therefore, it became imperative that these nurses share their experiences, challenges, and perceptions as they struggle with responding to the needs of patients and their families.

The National Association of Nigerian Nurses in North America (NANNNA), a non-profit organization felt it was crucial for its' members to tell their own stories. NANNNA is a united organization of all the Nigerian Nurses Associations and Nursing School Alumni in North America working to improve the health and quality of lives of Nigerians and their communities. To explore its members' participation in COVID-19 care and gain insight into their experiences, NANNNA conducted a poll among its members regarding their perspectives, especially in the early weeks of the outbreak. This was particularly important for NANNNA to help the organization respond to members' needs.

In addition to professional and COVID-19 related issues, Nigerian nurses also 
battled with myths and misconceptions about COVID-19 in their families and communities due to documented superstitions and ignorance of the science behind the COVID-19 infection among some Nigerians [7]. According to Olapegba, et al., some Nigerians will prefer to pray in groups, attend churches and mosques thereby ignoring the social and physical distancing guidelines. They further contend that Nigerians use WhatsApp chats and groups to spread fear and undermine the seriousness of the pandemic. Some nurses may experience avoidance by their family members and stigma or labeling as disease carriers by their community members. A statement put forth by the World Health Organization (WHO) in March 2020 [8] revealed that some healthcare workers are experiencing avoidance by their family or community owing to stigma or fear. It is hoped that information generated from the project will highlight important issues to inform strategies and programs that will better support nurses, other healthcare professionals especially those in the frontline during current and future infectious disease outbreaks. It will also help to strategize about community educational outreaches to address myths and misconceptions about COVID-19, especially in the Nigerian communities.

\section{Description, Analysis, and Discussion}

This report highlights experience of Nigerian nurses in the early weeks and surge of the COVID-19 pandemic. At the epic of the pandemic and as Covid-19 changed daily, that fundamentally changed the clinical work environment in ways that threaten nurses' emotional resilience and well-being. NANNNA leadership, with their early experiences at the frontline, used their expertise and skills to help other nurses by starting a daily support group for the nurses using NANNNA platform. The support group was from $5 \mathrm{pm}$ to $7 \mathrm{pm}$ EST daily, which was outstanding and remarkable, as nurses from different specialties and settings called in every day to share their experiences at the frontline. There were nurses who were struggling with their own health or that of a loved one and some who suffered loss that can seem impossible to bear. NANNNA leadership held the nurses in the light and were there to offer whatever comfort they could. To reach out to more Nigerian nurses and find out what they could be going through during the surge, recurring themes from the daily support group debriefing were used to prepare a brief guide, listing few closed and open-ended questions, with appropriate probes/prompts. Invitation was sent through emails and WhatsApp groups and was opened to Nigerian nurses at the frontline. Completing the survey was voluntary and anonymous. Survey asked questions about availability of personal protective equipment, training and educational preparation for care and perceptions of institutional support.

\section{Highlights of Finding}

This document summarizes the report expressed by Nigerian nurses faced with the challenges of the COVID-19 pandemic. This summary was guided by the 
phenomenological approach whose central aim is to understand the meaning of experiences of other people, and to understand both the positives and negatives of their lived experiences [9]. Guided by this viewpoint, the Nigerian nurse participants practicing under various unfavorable environments, gave voice to their lived experience in working in the frontlines during this COVID 19 pandemic. An in-depth analysis of the generated recurring themes was conducted to tease out the overarching themes and give clarity to the meaning of the Nigerian nurses' experience during the early weeks of COVID-19 pandemic [10]. One hundred and fourteen Nigerian nurses willingly participated in this project (Female $=88.6 \%$, Male $=11.4 \%$ ), with ages ranging from 28 years to 63 years. Some of the concerns shared include fear due to lack of personal and family safety, feeling unprotected due to lack of or inadequate PPE, inadequate training and educational preparation and support for safe practice given the contagious nature ness of the coronavirus disease.

\subsection{Fear Due to Lack of Personal and Family Safety}

Nigerian nurses expressed fear for their personal safety and that of their family members. Some of the fear arose from having pre-existing health conditions which made them more susceptible to the disease. Some expressed fear of getting re-infected after recovering from the infection and possibly exposing their families to the disease. One nurse said, "I am afraid of reinfecting myself as I am recovering from the infection as well as exposing my family ... to the virus". Another reported; "worried that I will bring COVID-19 home to my family". Yet another nurse expressed uncertainty and fear of the unknown such as, I don't know what my fate will be during and after the end of my shift". It was evident through the conversations that the rising infection rates as shown by the magnitude of patients' sickness, deterioration, and death, as well as suffering experienced by exposed colleagues to the deadly virus contributed to a considerable amount of stress, anxiety, and fear of the unknown.

\subsection{Feeling Unprotected Due to Lack of or Inadequate PPE}

There was a general feeling of being unprotected due to lack of or inadequate PPE in most of the healthcare environments and support from leadership and management. Figure 1 and Figure 2 displays the raw average percentages of nurses who expressed feeling unprotected due to lack of PPE. Majority, 66.36\% $(\mathrm{n}-71)$ of the participants reported that their facilities do not have adequate PPE (respirators, eye protection, face shield, gloves). Many of the participants $45.79 \%(n-49)$ were in the category of those who reported that their facilities do not have available $\mathrm{N} 95$ respirators.

Hence, majority of the nurses expressed feeling unprepared to care for patients with known or suspected COVID 19 diagnosis (Figure 3). Interestingly, majority of the nurses reported that their facilities did not even provide N95 respirators fitting test (Figure 4). The above factors related lack or inadequate 


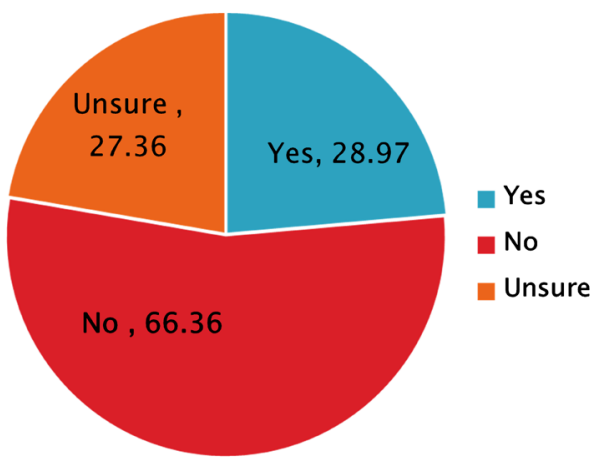

Figure 1. Percentage of participants who reported that their facilities do not have adequate PPE $(\mathrm{N}=114)$.

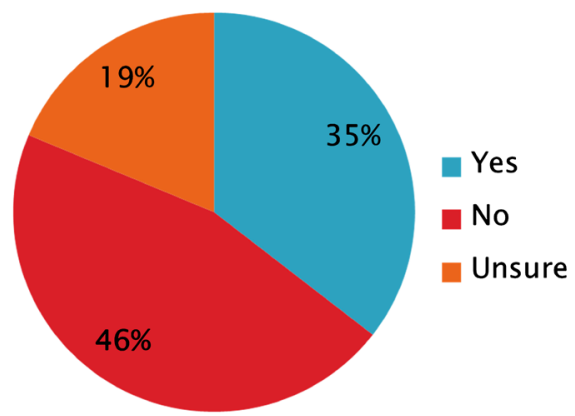

Figure 2. Percentage of participants reported that their facilities do not have available N95 respirators $(\mathrm{N}=114)$.

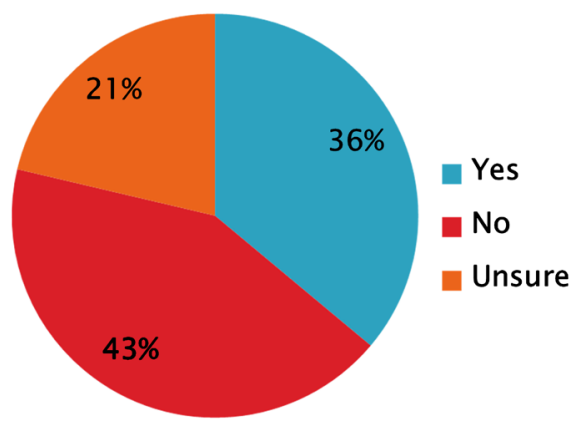

Figure 3. Participants reported that they do not feel prepared to provide care for a patient with known or suspected COVID-19 $(\mathrm{N}=114)$.

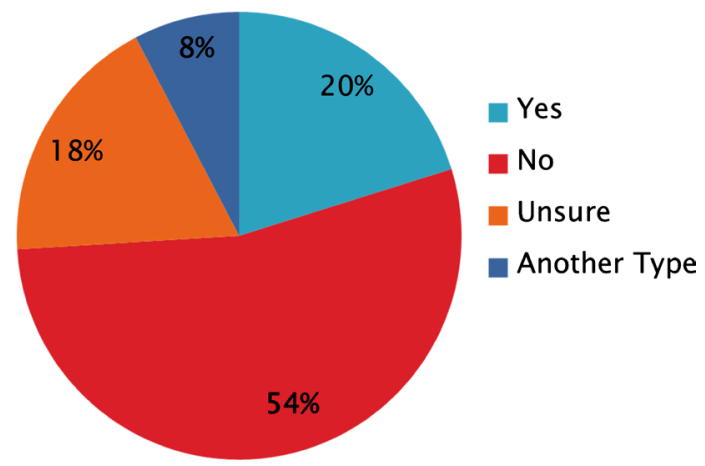

Figure 4. Percentage of participants who reported that their facilities do not provide N95 respirators fitting test $(\mathrm{N}=114)$. 
PPE's propagated the nurses' feeling of being unprotected when caring for patients who are suspected or known to have the disease.

When asked what additional information nurses need to feel safe and informed, some of the comments include: "Have the necessary safety garments, gloves, eye protection glasses, boot covers, and head gears". Another nurse shared; "Not reusing a disposable PPE would make me feel safer". Another concern of inadequate PPE raised by the participants of this project was the anxiety that patients initially not presenting with symptoms, and who did not require the use of PPE while caring for them can be later diagnosed with COVID-19.

\subsection{Inadequate Training/Educational Preparation and Support for Safe Practice}

Obtaining proper education, training and awareness was another concern expressed by the Nigerian nurses. Majority of the nurses felt that they were not adequately prepared in the form of training and or receiving regular and timely updates. Most of them felt that nurses should have been routinely educated on steps to prevent exposure, and provided with webinars geared towards enhancing their knowledge, given the evolving nature of the pandemic. They expressed a need for additional education and training through statements such as: "Educate members on the various stages of COVID-19 infection", "Regularly remind nurses on the need to protect themselves and steps to take in case of any suspected cases", "Regular webinar, information sharing and advocacy to governments", "Get updated always" and "More public enlightenment about COVID-19". "Advocate for the nurses because at the end of the day, they are the only ones left with the patients"

Some nurses reported a lack of support by their leadership or management team despite their dedication to care for the patients. This was supported with such comments as; 'in my facility, doctors were instructed not to enter patients' rooms unless they have a need to do so in order to minimize their risk of exposure while my co-workers and I go from one patient to another caring for them and leadership is okay with it". Some of the nurses reported reusing disposable PPEs as directed by their employers.

Among the Nigerian nurses in bargaining contract unions, they felt that the representatives should advocate for employers to procure PPE. One of the nurses said, "Unions should put pressure on facility management and the government to provide correct and adequate PPE to work with". Some of the nurses condemned the labor unions for losing sight on the importance of education and lack of advocacy at this critical time. These were captured in comments like: "The union can take up the responsibility of feeding its members with regular updates on the fight against COVID 19". One nurse however, acknowledged the efforts nurses' union by commenting that "The Nursing union have taken it upon themselves to re-educate members". It is possible that the Labor Union's efforts to assume educational role for nurses are evident in some areas than others. 


\section{Limitations of Report}

Data collection was performed early in the pandemic and perceptions may have changed over time. Data obtained from self-reported questionnaires were not verified with facility programs and initiatives to address the challenges posed by COVID-19 pandemic.

\section{Conclusions/Recommendations}

Protecting healthcare workers and preventing the spread of the disease are critical. As projections about the severity and duration of global and domestic outbreaks evolve, strategies to contain and mitigate the spread were put in place by many countries including Nigeria. Nigeria is one of the countries that have been greatly impacted by the virus in Africa. Till date, 61,667 cases have been confirmed, 56,880 cases discharged, and 1125 deaths recorded in 36 states and the Federal Capital Territory [11] [Figure 5, Figure 6].

At the beginning, Nigeria put together a presidential task force to coordinate, and disseminate information, alerts, warnings, and notifications to the public and incident management personnel. People got the messages of an unknown virus hitting the nation. Washing hands and social distancing were promoted at the beginning. Some states, especially the epicenter states were on lockdown. As the numbers of confirmed cases went up and the evidence and information about the virus evolved, wearing masks became the recommendation. Travel restrictions were also put in place [12]. However, the challenge was in compliance as most Nigerians did not take the pandemic seriously and many were afraid of stigmatization [13] [14]. The fear and stigma attached to the disease impacted nurses as well [15]. Some other resources they felt were a priority, including flexible time, increased staffing, stress management activities, and greater compensation,

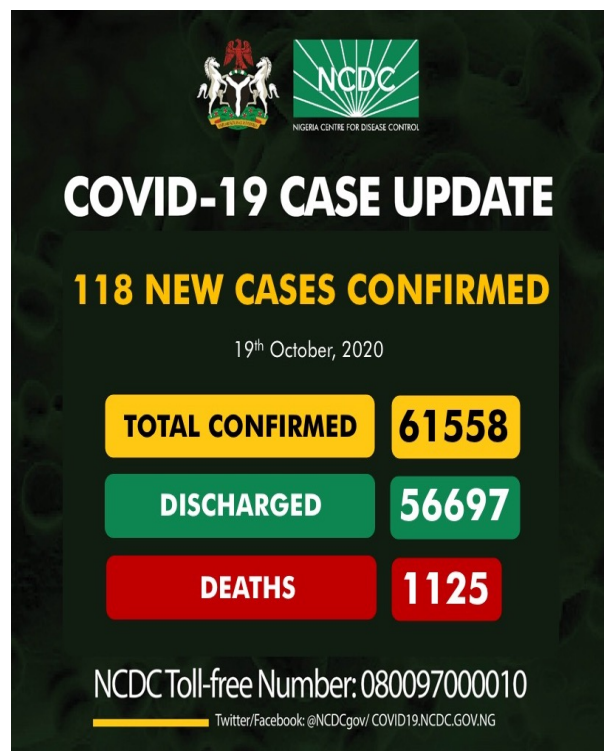

Figure 5. COVID 19 Statistics Update as of October 19, 2020 (Nigerian Center for Disease Control (NCDC). 


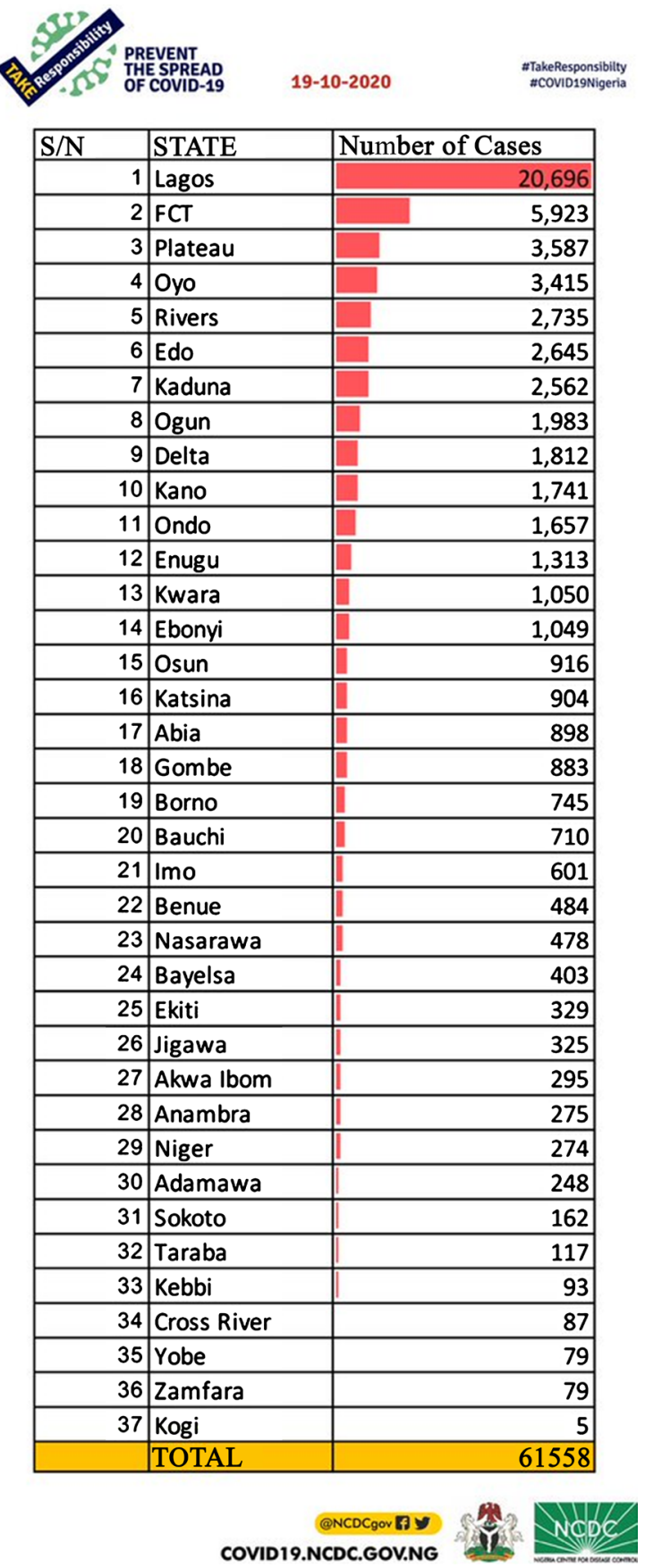

Figure 6. COVID 19 cases in States in Nigeria starting with those with the highest prevalence.

among other resources.

Clearly, the key points discussed highlight Nigerian nurses' voices and areas of concern during the COVID-19 pandemic. It was evident that participants of this project faced significant challenges in providing care to their patients such as inadequate PPE, reuse of disposable PPE, fear, and uncertainty. Particularly, Nigerian nurses expressed experiencing stigma in the community, being perceived as a threat to the safety of others for the fact that they are nurses and caring for 
individuals affected with Covid-19. This project reviewed that participants expressed lack of confidence on leadership to protect them. Therefore, it will be reasonable to conclude that COVID-19 has undoubtedly exposed some flaws in the global healthcare delivery system. It is our expectation that the issues raised will be given utmost consideration and thus enhance the support to these frontline healthcare workers. This report also highlights the need for a more in-depth study and programs to support nurses and other healthcare professionals during current and future infectious disease outbreak.

Public health emergencies such as Ebola and Covid-19 exemplify the need for the continual preparation of unexpected national events. Ensuring efforts made by all levels of governing bodies affords the safety of our society as well as paving the way for future points.

\section{Acknowledgements}

We would like to thank the Board members and Leadership of the National Association of Nigerian Nurses in America (NANNNA) for their support and insight. We would also like to thank the members of NANNNA Research Committee who contributed one way or another to the success of this report. We would like to especially thank Dr. Andrew Awoniyi for his assistance in disseminating this project question.

\section{Conflicts of Interest}

The authors declare no conflicts of interest regarding the publication of this paper.

\section{References}

[1] Smith, G.D., Ng, F. and Li, W.H.C. (2020) COVID-19: Emerging Compassion, Courage and Resilience in the Face of Misinformation and Adversity. Journal of Clinical Nursing, 29, 1425. https://doi.org/10.1111/jocn.15231

[2] Khalid, I., Khalid, T.J., Qabajah, M.R., Barnard, A.G. and Qushmaq, I.A. (2016) Healthcare Workers Emotions, Perceived Stressors and Coping Strategies during a MERS-CoV Outbreak. Clinical Medicine and Research, 14, 7-14. https://doi.org/10.3121/cmr.2016.1303

[3] Chen, S.-C., Lai, Y.-H. and Tsay, S.-L. (2020) Nursing Perspectives on the Impacts of COVID-19. Journal of Nursing Research, 28, e85. https://doi.org/10.1097/NRJ.0000000000000389

[4] Treston, C. (2020) COVID-19 in the Year of the Nurse. Journal of Association of Nurses in AIDS Care, 31, 359-356. https://doi.org/10.1097/JNC.0000000000000173

[5] Aljazeera (2020) Feature-Africa. Health Care Workers across Africa Share Their Coronavirus. Stories.

https://www.aljazeera.com/indepth/features/healthcare-workers-africa-share-coron avirus-stories-200427161407819.html

[6] Luis, C. and Vance, C. (2020) A Pandemic Crisis: Mentoring, Leadership, and the Millennial Nurse. Nursing Economics, 38, 152-163.

[7] Olapegba, P.O., Ayandele, O., Kolawole, S.O., Oguntayo, R., Gandi, J.C., Dangiwa, 
A.L., Iorfa, S.K., et al. (2020) COVID-19 Knowledge and Perceptions in Nigeria. https://doi.org/10.31234/osf.io/j356x

[8] Bagcchi, S. (2020) Stigma during the COVID-19 Pandemic. The Lancet Infectious Diseases, 20, 782. https://doi.org/10.1016/S1473-3099(20)30498-9

[9] Munhall, P.L. (2012) Nursing Research: A Qualitative Perspective. 5th Edition, Jones \& Bartlett Learning, Sudbury.

[10] Gray, J.R., Grove, S.K. and Sutherland, S. (2017) Burns \& Grove's the Practice of Nursing Research: Appraisal, Synthesis, and Generation of Evidence. 8th Edition, Elsevier, St. Louis.

[11] COVID-19 Nigeria, Confirmed Cases by State [Online]. https://covid19.ncdc.gov.ng

[12] Omaka-Amari, L., Aleke, O.C., Obande-Ogbuinya, E.N., Ngwakwe, C.P., Nwankwo, O. and Afoke, N.E. (2020) Coronavirus (COVID-19) Pandemic in Nigeria: Preventive and Control Challenges within the First Two Months of Outbreak. African Journal of Reproductive Health, 24, 87-97.

https://www.ajrh.info/index.php/ajrh/article/view/2294

[13] Obezu, T. (2020) Fear and Stigma Keep Nigerians from Helping Contact Tracers. VOA.

https://www.voanews.com/africa/fear-stigma-keep-nigerians-helping-contact-tracer s

[14] WHO Africa (2020) Social Stigma Threatens COVID-19 Response But Patients Heal Faster with Everyone's Support.

https://www.afro.who.int/news/social-stigma-threatens-covid-19-response-patientsheal-faster-everyones-support

[15] Bagcchi, S. (2020) Stigma during the COVID-19 Pandemic. The Lancet Infectious Diseases, 20, 782. https://doi.org/10.1016/S1473-3099(20)30498-9 